\title{
Tobacco control in Europe: a policy review
}

\author{
Roberto Bertollini ${ }^{1}$, Sofia Ribeiro ${ }^{1}$, Kristina Mauer-Stender ${ }^{2}$ and Gauden Galea ${ }^{2}$ \\ Affiliations: 'WHO Office at the European Union, Brussels, Belgium. ${ }^{2}$ WHO Regional Office for Europe, \\ Copenhagen, Denmark.
}

Correspondence: Roberto Bertollini, WHO Office at the European Union, 14, Rue Montoyer, Brussels B-1000, Belgium. E-mail: bertollinirdaweu.who.int

ABSTRACT Tobacco is responsible for the death of 6 million people every year globally, of whom 700000 are in Europe. Effective policies for tobacco control exist; however, the status of their implementation varies across the World Health Organization (WHO) European Region. In order to tackle the tobacco epidemic, action has been taken though the implementation of both legally binding and non-legally binding measures. This article aims to present the achievements and challenges of tobacco control in Europe, focussing on the available legally binding instruments such as the WHO Framework Convention on Tobacco Control and the revision of the Tobacco Products Directive at the European Union level. Tobacco still faces heavy lobbying of the tobacco industry, which has systematically contrasted policies to achieve public health objectives. The legal instruments for tobacco control in Europe presented here are not always adequately enforced in all the countries and there is certainly room for improving their implementation. Finally, the need for a strong political commitment towards the end-game of the tobacco epidemic is emphasised.

$\boldsymbol{O}$ @ERSpublications

We can stop the epidemic of tobacco-related diseases but we need political commitment to the endgame of this epidemic http://ow.ly/10lEFC

\section{Introduction}

Tobacco smoking (the World Health Organization (WHO) defines tobacco products as "products made entirely or partly of leaf tobacco as a raw material, which are intended to be smoked, sucked, chewed or snuffed" [1]; all these products contain nicotine, which is considered a highly addictive substance [2]) is responsible for the death of around 6 million people every year at the global level: more than 5 million deaths result from direct tobacco use and more than 600000 from exposure to second-hand smoke [3]. In the European Union (EU), the total number of deaths related to tobacco is almost 700000 per year, tobacco being the single largest cause of preventable deaths in the region [4].

The WHO European Region has the highest current adult (age 15 years and over) tobacco use among all the WHO Regions. Approximately $41 \%$ of men and $22 \%$ of women currently smoke tobacco products. $22 \%$ is a high average compared to those for women in Africa, Asia and the Middle East (3-5\%). While tobacco use in Europe was previously largely a male phenomenon, the gap in prevalence between male and female adults is now very small in countries such as Austria, Denmark, Ireland, the Netherlands and the UK, and closing in others. In Sweden and Norway, the prevalence of daily tobacco smoking is higher in women. Similarly, more girls than boys are using tobacco in Bulgaria, Croatia, Poland and Slovenia [5]. Differences in the proportion of people exposed to second-hand smoke are also observed among EU Member States: the differences are greater in young people and people facing financial difficulties [6].

Effective policies for tobacco control exist and are proven to decrease the prevalence of tobacco use. For example, health-related warnings on cigarette packages, especially those that use pictures, have been shown to decrease the number of young people who start smoking and increase the number of tobacco users who quit. A review of studies conducted in countries that have implemented this policy have shown that pictorial warnings raise awareness of tobacco-related harm and decrease consumption [7]. A study with

Received: March 012016 | Accepted after revision: March 252016

Conflict of interest: None declared.

Provenance: Submitted article, peer reviewed.

The content of this work is @the authors or their employers. Design and branding are OERS 2016. ERR articles are open access and distributed under the terms of the Creative Commons Attribution Non-Commercial Licence 4.0. 
data from the Eurobarometer survey also showed that these measures are likely to have an impact on smoking behaviour among EU citizens [8]. Bans on advertising, promotion and sponsorship combined can also decrease tobacco consumption by an average of 7\% [9]. High taxation of tobacco products to increase their cost for the consumers is highly effective: a tax that increases tobacco prices by $10 \%$ results in an average decrease on tobacco consumption of $4 \%$ in high income countries and by $5 \%$ in low income countries [10]. Antitobacco information is associated with quitting intentions and negative attitudes towards tobacco [11]. Evidence also shows that tobacco policies need to include the whole range of tobacco products such as roll-your-own cigarettes, water pipes and cigars [12].

Because of the high human, social and economic cost to society, over the years, national and international authorities have undertaken actions to reduce tobacco consumption, promoting the implementation of effective regulations for production, marketing and consumption. National and local policies have been inspired by international agreements and legislation that have been developed to facilitate a coordinated and homogeneous global response to the global threat to health and the economy posed by tobacco consumption. For example, the World Bank Group Tobacco Control Program assists countries in the implementation of tobacco taxation and to control illicit trade of tobacco [13]. Six policies were proposed by the World Bank, including price increases, bans/restrictions on smoking, better consumer information, comprehensive bans on advertising, health warning labels and access to smoking cessation treatment [14].

This article aims to review to what extent tobacco control policies have been and are being implemented in Europe, on the basis of the existing international instruments and legislation.

\section{The WHO Framework Convention on Tobacco Control}

The WHO Framework Convention on Tobacco Control (FCTC) was developed with the aim of tackling the causes of the tobacco epidemic. These include trade liberalisation, foreign investment, tobacco advertising, cross-border promotion and sponsorship, and illicit trade of tobacco and tobacco products.

The FCTC is the first global public health treaty based on evidence and is an international, legally binding instrument. It reaffirms the right of all people to the highest standard of health and provides new legal dimensions for cooperation in tobacco control. As with any other treaty, the WHO FCTC confers legal obligations to the countries that have signed it and binds them to comply with its regulations.

The Convention entered into force on the February 27, 2005, after being acceded, ratified, accepted or approved by 40 states. Countries that have adhered to the Convention are named Parties: currently, the FCTC has 180 Parties. The Conference of the Parties is the governing body of the FCTC and is composed of all Parties to the convention.

The FCTC is divided into 10 parts, each containing a number of articles, addressing specific aspects related to tobacco control. Article 5.3 is considered one of the most important provisions of the convention, as it requires Parties to protect both tobacco control and public health policies from the vested interests from tobacco industry. Implementation guidelines for this article have been adopted. Table 1 summarises the main issues within the FCTC [15].

Global progress reports and implementation guidelines were created to facilitate the implementation of the articles in the Convention. In addition, based on article 15 of the WHO FCTC, a protocol to eliminate illicit trade in tobacco products was approved in November 2012 and is in the process of ratification. In this context, illicit trade was considered to be any practice related to producing, shipping, receiving, being in possession of, distributing, selling or buying that is prohibited by law. This protocol covers the topics of supply chain control (manufacturing), offences to noncompliers, international cooperation, reporting obligations, institutional arrangements and financial resources, and statement of disputes [16].

The implementation of the provisions of the FCTC in the WHO European Region has been analysed [17]. The assessment provided a mixed picture and a low implementation rate was observed for several indicators (table 2). This shows both the difficulty of putting international agreements into place and practice, and perhaps the pressure from the tobacco lobby to delay and postpone effective measures of tobacco control.

In 2013, the Tobacco Control Scale (TCS) study was conducted in 34 European countries and ranked countries according to their TCS score. This score was based on price per pack, public place bans, public information campaign spending, advertising bans, health warnings and treatment. There were four leading countries (the UK, Ireland, Iceland and Norway) but 24 countries still did not reaching 50 points out of a total of 100 [18].

\section{The Tobacco Products Directive}

The first EU Tobacco Products Directive (TPD), which regulated aspects such as manufacture, sale and presentation of tobacco products, was approved in 2001 (directive 2001/37/EC). 
TABLE 1 The World Health Organization Framework Convention on Tobacco Control [14]: overview and summary of main sections

\begin{tabular}{|c|c|}
\hline Section & Articles \\
\hline I) Introduction & $\begin{array}{l}\text { 2) "[...]members are encouraged to implement measures } \\
\text { beyond those required by this Convention[...]" }\end{array}$ \\
\hline $\begin{array}{l}\text { II) Objective, guiding principles and general } \\
\text { obligations }\end{array}$ & $\begin{array}{l}\text { 3-5) Establish the objective, guiding principles and } \\
\text { general obligations engendered by the treaty }\end{array}$ \\
\hline $\begin{array}{l}\text { III) Measures related to the reduction of } \\
\text { demand for tobacco }\end{array}$ & $\begin{array}{c}\text { 6-14) Demand side reduction measures, including } \\
\text { smoking indoors, contents of tobacco products, } \\
\text { packaging and labelling, training and public awareness, } \\
\text { tobacco advertising, and support for reducing } \\
\text { tobacco dependence and cessation }\end{array}$ \\
\hline $\begin{array}{l}\text { IV) Measures relating to the reduction of } \\
\text { supply of tobacco }\end{array}$ & $\begin{array}{l}\text { 15-17) Eliminating illicit trade of tobacco products, } \\
\text { prohibition of selling tobacco to underage persons and } \\
\text { provision of economically viable alternative activities }\end{array}$ \\
\hline V) Protection of the environment & $\begin{array}{c}\text { 18) Risks of tobacco growing to human health } \\
\text { and to the environment }\end{array}$ \\
\hline VI) Questions related to liability & $\begin{array}{c}\text { 19) Taking legislative action or promoting their } \\
\text { existing laws to deal with liability }\end{array}$ \\
\hline $\begin{array}{l}\text { VII) Scientific and technical cooperation and } \\
\text { communication of information }\end{array}$ & $\begin{array}{l}\text { 20-22) National and international research surveillance } \\
\text { for tobacco control, reporting on the implementation of } \\
\text { the Convention, and cooperation to strengthen capacity } \\
\text { for implementing the Convention }\end{array}$ \\
\hline $\begin{array}{l}\text { VIII) Institutional arrangements and financial } \\
\text { resources }\end{array}$ & $\begin{array}{l}\text { 23-26) Establishment and convening of sessions of the } \\
\text { COP, functions of the Convention secretariat, relations } \\
\text { between the COP and intergovernmental organisations, } \\
\text { and financial support for national programmes }\end{array}$ \\
\hline $\begin{array}{l}\text { IX-X] Settlement of disputes and } \\
\text { development of the Convention }\end{array}$ & $\begin{array}{l}\text { 28-29] Development of the convention } \\
\text { 30-38] "Final provisions" covering statutory } \\
\text { matters such as means of acceding to the } \\
\text { Convention, entry into force, etc. }\end{array}$ \\
\hline
\end{tabular}

COP: Conference of the Parties.

8 years later, in 2009, under the pressure of the public health community, and following scientific and market-related developments, the European Commission decided to review the TPD. The entry into force of the WHO FCTC in 2005 also contributed to stress the need for this revision, as a number of EU countries also became Parties of the Convention and supported a coherent approach to the problem across different legal instruments.

The whole process started in February 2009 with an Impact Assessment (IA) that lasted until July 2012. The IA comprised Eurobarometer surveys, a public consultation, stakeholder meetings, and opinions of other committees and European bodies. The proposal was finally adopted by the College of Commissioners in December 2012, almost 4 years after the process had started. The ordinary legislative process began immediately after this, on January 2013, finishing in April 2014, when the final act was signed.

TABLE 2 Full implementation of the Framework Convention on Tobacco Control (FCTC) main indicators in the 53 countries in the World Health Organization (WHO) European Region

Indicator

Countries with full implementation

\begin{tabular}{|c|c|}
\hline Ratification of the WHO FCTC & $50(94.3 \%)$ \\
\hline Raise tobacco taxes $\#$ & $29(54.7 \%)$ \\
\hline Laws on smoke-free public places ${ }^{\pi}$ & $10(18.9 \%)$ \\
\hline Cessation programmes ${ }^{+}$ & $8(15.1 \%)$ \\
\hline Ban on advertising, promotion and sponsorship $\S$ & $4(7.6 \%)$ \\
\hline Pictorial warnings labels on packaging ${ }^{f}$ & $3(5.7 \%)$ \\
\hline
\end{tabular}

\#: more than $75 \%$ of the price is tax; ${ }^{\text {I: }}$ all public places are completely smoke-free or at least $90 \%$ of the population is covered by complete subnational smoke-free legislation; ${ }^{+}$: the country has a national quit line, and both nicotine replacement therapy and some cessation services are cost covered; ${ }^{\S}$ : a ban on all forms of direct and indirect advertising; ${ }^{f}$ : should be large, with all appropriate characteristics. Data from [17]. 
The revision of the TPD was considered as "the most lobbied dossier in the history of the EU institutions" [19] and Phillip Morris International, the biggest stakeholder from the tobacco industry, employed more than 160 lobbyists and spent around $€ 1.25$ million on lobbying on the TPD dossier [20]. There is scientific evidence showing that the final text of the TPD was influenced by the intensive tobacco industry lobbying and was less protective of the health of EU citizens [21]. It is important to note that the FCTC, of which the European Commission (EC) is one of the Parties, specifies in Article 5.3 that Parties have to take precautionary measures to protect tobacco policies from industry lobbying. The enforcement of this article was quite weak during the process of discussion and approval of the TPD as there were several meetings with tobacco lobbyists that were not publicly disclosed [22]. In addition, there is evidence that tobacco industry interference caused a delay in the legislative process [23].

One of the key provisions of the TPD refers to the size and position of health warnings. Increased sizes of pictorial and textual Health Warning Labels are known to be one of the most cost-effective instruments to inform consumers about the health risks of using tobacco products [24]. In the initial proposal, these warnings were supposed to occupy $75 \%$ of the front, back and top of the package, while in the final TPD text, this percentage was reduced to $65 \%$. The ban on "characteristic flavours", which make tobacco products more appealing to certain population groups, was present in the first draft but not in the final text; though flavours were still banned, menthol, one of the most commonly used flavourings, had a 4-year derogation in implementation. Although a slim cigarette ban and a ban on 10-cigarette packs were introduced in the first draft, only the ban on 10-cigarette packs remained in the final draft. Mandatory age verification for cross-border distance sales was left at Member State discretion in the final text. In the first version, the EC proposed that tracking and tracing of tobacco products were extended to the whole supply chain but in the end, it remained solely mandatory for the legal supply chain. Electronic nicotine delivery systems, of which e-cigarettes are a part, were requested to have a medicinal license depending on nicotine concentration in the first TPD version. However, in the last version, a medicinal license for these products was kept as mandatory only if these products were associated with health claims. Finally, the ban on snus (tobacco product for oral use typically consumed in Sweden) continues to be applied throughout the EC, with the exception of Sweden.

The TPD, being an EU Directive, will have to be transposed by EU Member States onto their national legislation. They will have to implement and comply with the measures stated there. For noncompliant Member States, there might be sanctions applied by the EC. The final deadline for transposition (incorporating the TPD into national law) was May 2016 [25].

\section{Status of policy implementation in Europe: the 2014 TPD}

$12(42.9 \%)$ countries have fully transposed the TPD, 5 months before the established deadline for transposition, while three countries have performed a partial or unofficial transposition. However, 13 (46.4\%) countries are still behind on this issue.

Figure 1 presents an overview of the status of the transposition of the TPD, by country, updated in November 2015. It needs to be made clear that transposition is not "implementation". The TPD is going to be supported by a number of implementing acts, which will be included in national legislation [26]. They have first to be finalised by the EC. Then, Member States have an additional 6-12 months to implement the TPD, starting from May 2016.

In October 2015, an implementing act specifying the health warnings on tobacco products for smoking, including cigarettes and roll-your-own tobacco, was approved. These health warnings, required by the TPD, should comprise a photograph in colour, a text part on smoking-related harm and information on smoking cessation. Health warnings should be present in tobacco packages across the whole EU by May 2016 [27].

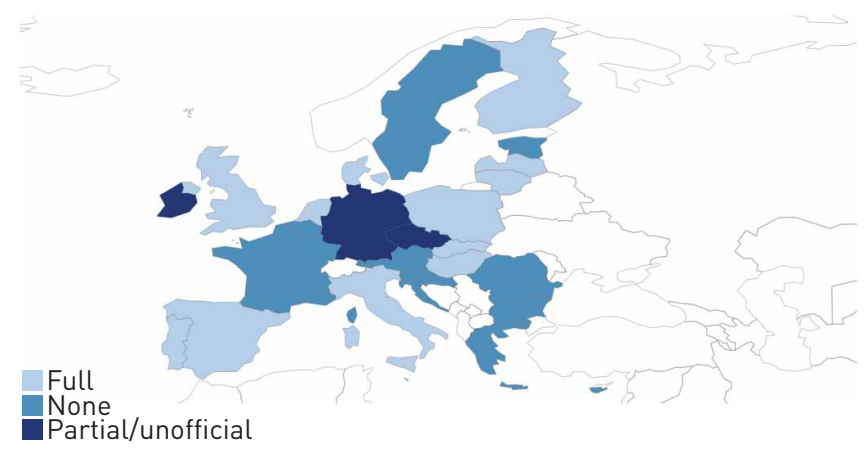

FIGURE 1 Status of the transposition of the European Union Tobacco Products Directive onto national legislation. 
In November 2015, the Commission approved a decision that established a common format for the reporting of information on ingredients and emissions of tobacco products. This decision contains six articles; and manufacturers and importers of tobacco products are obliged to submit information on ingredients, emissions and sale volumes of tobacco products electronically to Member States. This policy supports the implementation of Articles 9 and 10 of the FCTC, and facilitates the processing, comparison and analysis of data on tobacco control by the Member States and the EC [28].

\section{Other international instruments for tobacco control}

A number of non-legally binding instruments, such as WHO and United Nations (UN) resolutions, or declarations made at the end of official meetings, have addressed tobacco control over the years. For the second time in history, after dealing with HIV/AIDS in 2001, the UN General Assembly in 2011 convened a high-level meeting on prevention and control of noncommunicable diseases (NCDs) in New York, NY, USA. At this meeting, a resolution expressing the political commitment of world leaders to address NCDs was adopted [29]. More recently, tobacco control has featured as a key component of the WHO Global Strategy for the Control of Non-Communicable Diseases and its related action plan 2013-2020 [30]. This action plan proposes a target of a $30 \%$ relative reduction in the prevalence of existing tobacco use in persons older than 15 years of age by 2025 [31]. Tackling NCDs is also a priority under the Health 2020 strategy, the WHO European policy framework for health and well-being [32].

In July 2015, the United National General Assembly endorsed the outcome of the Third International Conference on Financing for Development, also called the Addis Ababa Action Agenda [33]. This Agenda recognises that tobacco price and tax measures can be important means to reduce tobacco consumption and health-related costs, but are also useful for financing development in general terms.

In September 2015, the 2030 Agenda for Sustainable development was adopted at the United National General Assembly [34]. This global agenda includes 17 goals that all countries have agreed to achieve by 2030. Goal 3 aims of to achieve healthy lives and promote wellbeing at all ages, and includes a specific reference target encouraging strengthened

At the recent meeting in Vilnius, Lithuania, of the 53 countries of WHO Europe, a roadmap of actions to strengthen the implementation of the WHO FCTC in the European Region for the period between 2015 and 2025 has been approved [35]. The aim of this resolution is "making tobacco a thing from the past", urging Member States to set up mechanisms for implementation of multisector tobacco policies, including funding and strengthening national capacity, and building intersector alliances and networks.

\section{Conclusions and future actions}

Tobacco smoking remains the single most important risk factor for NCDs [36]. Much is known about the health risks and the effective preventive strategies to reduce tobacco consumption and its harm to health. Awareness of the risks to health associated with tobacco use is wide and evidence shows that there is consistent public support to a complete ban on use or sale of tobacco: $34.9 \%$ of adults in 18 European countries are in favour of a tobacco endgame strategy [37]. Despite the amount of evidence available, effective action, defined and encouraged by international commitments, is contrasted by the heavy lobbying of the tobacco industry using a number of strategies to conquer new customers and oppose action at all levels. The consistency of this interference and the huge amount of resources made available for this by the tobacco companies may be one of the reasons why international agreements and commitments for tobacco control are not always adequately enforced or their implementation is delayed. Each month of delay means huge financial gains for the tobacco industry, and huge losses for our health and societies [38].

In conclusion, we have the knowledge and instruments to stop the epidemic of tobacco-related diseases but we need strong and consistent political commitment to initiate and sustain the endgame of the tobacco epidemic $[1,39]$. In this context, medical professionals need to play their role in full, and contrast in a transparent and effective way the interference of the tobacco industry [2].

\section{References}

World Health Organization. Tobacco. www.who.int/topics/tobacco/en/ Date last updated: 2016.

2 Rabe KF, Gratziou C, Ward B, et al. Towards a total ban on links with the tobacco industry: new rules for the ERS. Eur Respir J 2012; 40: 809-810.

3 World Health Organization. Tobacco. www.who.int/mediacentre/factsheets/fs339/en/ Date last updated: July 6, 2015.

4 European Commission. Directive of the European Parliament and of the Council on the approximation of the laws, regulations and administrative provisions of the Member States concerning the manufacture, presentation and sale of tobacco and related products. http://ec.europa.eu/health/tobacco/docs/com_2012_788_en.pdf Date last updated: December 19, 2012. 
5 WHO Europe. Who is smoking? www.euro.who.int/en/health-topics/disease-prevention/tobacco/data-and-statistics/ who-is-smoking Date last updated: 2016.

6 Filippidis FT, Agaku IT, Girvalaki C, et al. Relationship of secondhand smoke exposure with sociodemographic factors and smoke-free legislation in the European Union. Eur J Public Health 2015; DOI: 10.1093/eurpub/ckv204

7 Hammond D Health warning messages on tobacco products: a review. Tob Control 2011; 20: 327-337.

8 Agaku IT, Filippidis FT, Vardavas CI. Effectiveness of text versus pictorial health warning labels and predictors of support for plain packaging of tobacco products within the European Union. Eur Addict Res 2015; 21: 47-52.

9 The World Bank. Curbing the epidemic - governments and the economics of tobacco control. http://documents. worldbank.org/curated/en/1999/05/437174/curbing-epidemic-governments-economics-tobacco-control Date last updated: April 25, 2001.

10 International Agency for Research on Cancer. Effectiveness of Tax and Price Policies for Tobacco Control. www.iarc.fr/en/publications/pdfs-online/prev/handbook14/handbook14-0.pdf Date last updated: 2011.

11 Springvloet L, Willemsen MC, Mons U, et al. Educational differences in associations of noticing anti-tobacco information with smoking-related attitudes and quit intentions: findings from the International Tobacco Control Europe Surveys. Health Educ Res 2015; 30: 719-730.

12 Lidón-Moyano C, Martín-Sánchez JC, Saliba P, et al. Correlation between tobacco control policies, consumption of rolled tobacco and e-cigarettes, and intention to quit conventional tobacco, in Europe. Tob Control 2016 [in press DOI: 10.1136/tobaccocontrol-2015-052482].

13 The World Bank. Tobacco Control Program. www.worldbank.org/en/topic/health/brief/tobacco Date last updated: December 14, 2015.

14 The World Bank. Tobacco control at a glance. http://siteresources.worldbank.org/INTPH/Resources/3760861238076532997/TobaccoControl2010Nov15.pdf Date last updated: 2003.

15 World Health Organization. The WHO Framework Convention on Tobacco Control: an overview. www.who.int/ fctc/WHO_FCTC_summary_January2015_EN.pdf?ua=1 Date last updated: 2015.

16 World Health Organization. The Protocol to Eliminate Illicit Trade in Tobacco Products: an overview. www.who. int/fctc/Protocol_summary_en.pdf?ua=1 Date last updated: 2015.

17 World Health Organization. Infographic - WHO FCTC implementation 2015. www.euro.who.int/en/healthtopics/disease-prevention/tobacco/data-and-statistics/infographic-who-fctc-implementation-2015-download Date last updated: 2016.

18 Joossens L, Raw M. The Tobacco Control Scale 2013 in Europe. A report of the Association of European Cancer Leagues. Brussels, Association of European Cancer Leagues, 2014.

19 Corlett N. ALDE priorities for the week of 23 Sept 2013. www.vieuws.eu/previeuws/parliament-agenda-aldepriorities-for-the-week-of-23-sept-2013/ Date last updated: September 23, 2013.

20 Philip Morris International. Copy of the New Transparency Register. List of Consultants and Their Expenses. New York, PMI, 2013.

21 Costa H, Gilmore AB, Peeters S, et al. Quantifying the influence of the tobacco industry on EU governance: automated content analysis of the EU Tobacco Products Directive. Tob Control 2014; 23: 473-478.

22 Peeters S, Costa H, Stuckler D, et al. The revision of the 2014 European tobacco products directive: an analysis of the tobacco industry's attempts to 'break the health silo'. Tob Control 2016; 25: 108-117.

23 Doward J. Tobacco giant Philip Morris "spent millions in bid to delay EU legislation". www.theguardian.com/ business/2013/sep/07/tobacco-philip-morris-millions-delay-eu-legislation Date last updated: September 7, 2013.

24 Fong GT, Hammond D, Hitchman SC. The impact of pictures on the effectiveness of tobacco warnings. Bull World Health Organ 2009; 87: 640-643.

25 Council of the European Union, European Parliament. DIRECTIVE 2014/40/EU OF THE EUROPEAN PARLIAMENT AND OF THE COUNCIL of 3 April 2014 on the approximation of the laws, regulations and administrative provisions of the Member States concerning the manufacture, presentation and sale of tobacco and related products and repealing Directive 2001/37/EC. Off J Eur Union 2014; L127: 1-38.

26 European Commission. Implementing the Tobacco Products Directive (Directive 2014/40/EU). http://ec.europa.eu/ health/tobacco/products/revision/implementation_en.htm

27 World Health Organization. European Union: specifications for health warnings on cigarette packages adopted today. http://apps.who.int/fctc/implementation/database/groups/european-union-specifications-health-warningscigarette-packages-adopted-today Date last updated: October 12, 2015.

28 World Health Organization. European Union: Commission Implementing Decision (EU) 2015/2186 of 25 November 2015 establishing a format for the submission and making available of information on tobacco products. http://apps.who.int/fctc/implementation/database/groups/european-union-commission-implementingdecision-eu-20152186-25-november-2015-establishing

29 United Nations. Political declaration of the High-level Meeting of the General Assembly on the Prevention and Control of Non-communicable Diseases. www.un.org/ga/search/view_doc.asp?symbol=A/66/L.1 Date last updated: September 16, 2011.

30 World Health Organization. Global action plan for the prevention and control of noncommunicable diseases 2013-2020. http://apps.who.int/iris/bitstream/10665/94384/1/9789241506236_eng.pdf Date last updated: 2013.

31 World Health Organization. Follow-up to the Political Declaration of the High-level Meeting of the General Assembly on the Prevention and Control of Non-communicable Diseases http://apps.who.int/gb/ebwha/pdf_files/ WHA66/A66_R10-en.pdf Date last updated: May 27, 2013.

32 World Health Organization. Health 2020. A European policy framework and strategy for the 21st century. www.euro.who.int/_data/assets/pdf_file/0011/199532/Health2020-Long.pdf Date last updated: 2013.

33 United Nations. Addis Ababa Action Agenda of the Third International Conference on Financing for Development (Addis Ababa Action Agenda). www.un.org/esa/ffd/wp-content/uploads/2015/08/AAAA_Outcome. pdf Date last updated: 2015.

34 United Nations. Transforming our world: the 2030 Agenda for Sustainable Development (A/RES/70/1). www.un. org/ga/search/view_doc.asp?symbol=A/RES/70/1\&Lang=E Date last updated: October 21, 2015.

35 World Health Organization. Roadmap of actions to strengthen the implementation of the WHO Framework Convention on Tobacco Control in the European Region 2015-2025 www.euro.who.int/_data/assets/pdf_file/ 0009/288279/65rs04e_TobaccoRoadmap_150749.pdf?ua=1 Date last updated: September 16, 2015. 
36 World Health Organization. Global status report on noncommunicable diseases 2014. http://apps.who.int/iris/ bitstream/10665/148114/1/9789241564854 eng.pdf?ua=1 Date last updated: 2014

37 Gallus S, et al. Support for a tobacco endgame strategy in 18 European countries. Prev Med (Baltim) 2014; 67: 255-258.

38 Smoke Free Partnership. The cost of tobacco use. www.smokefreepartnership.eu/news/cost-tobacco-use

39 McDaniel PA, Smith EA, Malone RE. The tobacco endgame: a qualitative review and synthesis. Tob Control 2015 [in press DOI: 10.1136/tobaccocontrol-2015-052356]. 